\title{
Long-Lasting Inhibitory Effects of Distigmine on Recombinant Human Acetylcholinesterase Activity
}

\author{
Keisuke Obara, ${ }^{a}$ Daisuke Chino, ${ }^{a, b}$ and Yoshio Tanaka*,a \\ ${ }^{a}$ Department of Chemical Pharmacology, Faculty of Pharmaceutical Sciences, Toho University; 2-2-1 Miyama, \\ Funabashi, Chiba 274-8510, Japan: and ${ }^{b}$ Department of Pharmacotherapy, Faculty of Pharmaceutical Sciences, \\ Nihon Pharmaceutical University; 10281 Komuro, Ina-machi, Kita-Adachi-gun, Saitama 362-0806, Japan. \\ Received April 26, 2017; accepted July 13, 2017
}

\begin{abstract}
To elucidate the mechanism whereby distigmine, an underactive bladder remedy, potentiates urinary bladder contractions long-lastingly, the inhibition of recombinant human acetylcholinesterase (rhAChE) by distigmine was investigated. A centrifugal ultrafiltration device, Nanosep ${ }^{\circledR} 10 \mathrm{~K}$, was used to separate rhAChE and a bound inhibitor from an unbound inhibitor, reaction substrate, and reaction product. This allowed the same aliquot of $\mathrm{rhAChE}$ to be repeatedly assayed for up to $48 \mathrm{~h}$ to confirm the long-lasting binding of an inhibitor. Cholinesterase (ChE) inhibitors, distigmine, pyridostigmine, neostigmine, and ambenonium, were tested. The dissociation rate constant $\left(k_{\text {diss }}\right)$ and dissociation half-life $\left(t_{1 / 2}\right)$ of each inhibitor were determined based on the changes in rhAChE activity. Within $2-4 \mathrm{~h}$ after removing pyridostigmine, neostigmine, or ambenonium, the rhAChE activity was restored to the control levels. The $\boldsymbol{k}_{\mathrm{diss}}$ values for pyridostigmine, neostigmine, and ambenonium were calculated to be $0.51 \pm 0.05,0.66 \pm 0.03$, and $1.41 \pm 0.08 \mathrm{~h}^{-1}$, and the $t_{1 / 2}$ values were calculated to be $1.36,1.05$, and $0.49 \mathrm{~h}$, respectively. With distigmine, the rhAChE activity initially dropped to $17 \%$ of that in the control and then slowly recovered to only $50 \%$ by $48 \mathrm{~h}$ after drug removal. The $k_{\text {diss }}$ and $t_{1 / 2}$ values of distigmine were calculated to be $0.012 \pm 0.001 \mathrm{~h}^{-1}$ and $57.8 \mathrm{~h}$, respectively. Based on the $t_{1 / 2}$ values, distigmine was judged to dissociate from acetylcholinesterase (AChE) 40-120-fold slower than the other ChE inhibitors did. This may explain the long-lasting potentiation of urinary bladder contractions and motility by distigmine as a treatment for an underactive bladder.
\end{abstract}

Key words distigmine bromide; acetylcholinesterase; cholinesterase inhibitor

Distigmine is a reversible cholinesterase (ChE) inhibitor from the class of carbamates. It was chemically synthesized by Schmid $^{1)}$ and has a chemical structure consisting of two molecules of pyridostigmine connected by hexamethylene bonds (Fig. 1). Distigmine is used clinically in some Asian and European countries, including Japan and Germany, ${ }^{2-8)}$ and the main clinical indication for distigmine is myasthenia gravis. ${ }^{2,9)}$ However, in Japan, distigmine has also been used for glaucoma $^{3)}$ and an underactive bladder. ${ }^{4-8)}$

The effectiveness and usefulness of distigmine for underactive bladder treatment have been shown in many clinical studies. $^{4-8)}$ However, the experimental evidence to support these clinical reports was not convincing. Therefore, our laboratory started pharmacological studies on the effects of distigmine on urinary bladder (UB) motility and has previously reported results supporting the clinical effectiveness and usefulness of distigmine. ${ }^{10-18)}$ The most remarkable pharmacological characteristic of distigmine was the persistence of its effect. In particular, distigmine was found to potentiate the UB internal pressure via the micturition reflex for more than $12 \mathrm{~h}^{17 \text { ) }}$

Interestingly, the long-lasting potentiating effect of distigmine on intravesical pressure persisted even after distigmine disappeared from the blood. ${ }^{17)}$ In addition, the potentiating effect of distigmine on the acetylcholine (ACh)-induced contraction of isolated UB tissue lasted for $12 \mathrm{~h}$ after distigmine was removed. ${ }^{18)}$ Based on our pharmacological results, we have speculated about two possible mechanisms by which distigmine could exert its long-lasting effects on UB motility: 1) distigmine very strongly binds to acetylcholinesterase (AChE) and resists dissociation; 2) distigmine persists in UB plasma membranes and is gradually released to inhibit AChE. Of these two possibilities, we considered the former to be more likely and examined how long distigmine inhibited the AChE activity in isolated UB tissue. Consequently, we have found that distigmine inhibited the $\mathrm{AChE}$ activity in isolated $\mathrm{UB}$ tissue for $12 \mathrm{~h}$ even after removal of the drug. ${ }^{18)}$ However, the previous study was performed using UB smooth muscle tissues. Therefore, the second possibility, i.e., that distigmine remains in UB smooth muscle plasma membranes and is slowly released, could not be excluded.

The present study was thus carried out to obtain convincing evidence showing that distigmine directly inhibited the AChE activity for a long term. To achieve this objective, we examined for how long distigmine inhibited recombinant human $\mathrm{AChE}$ (rhAChE) and showed that the compound was bound to AChE very strongly and was difficult to dissociate.

\section{METHODS}

Measurement of rhAChE Activity rhAChE used in the present study ( $\geq 1000$ U/mg protein; C1682; Sigma-Aldrich, St. Louis, MO, U.S.A.) was purified from transfected HEK 293 cells. The freeze-dried product was dissolved in phosphatebuffered saline (PBS; $0.1 \mathrm{M}, \mathrm{pH} 7.4$ ) to obtain a stock solution of $\mathrm{rhAChE}$ at $0.1 \mathrm{mg} / \mathrm{mL}$, which was cryopreserved $\left(-28^{\circ} \mathrm{C}\right)$ and thawed immediately before use. The thawed rhAChE stock solution was diluted with a modified Hanks' balanced salt solution (HBSS) to a concentration of $0.017 \mathrm{mg} / \mathrm{mL}$ ( $c a$. 6-fold) to be used in subsequent experiments. The composition of $\mathrm{HBSS}$ was as follows (mM): $\mathrm{NaCl}, 136.9 ; \mathrm{KCl}, 5.37$; $\mathrm{CaCl}_{2}, 1.26 ; \mathrm{MgCl}_{2}, 0.81 ; \mathrm{Na}_{2} \mathrm{HPO}_{4}, 0.77 ; \mathrm{KH}_{2} \mathrm{PO}_{4}, 0.44$; $\mathrm{NaHCO}_{3}, 4.17$; glucose, 5.55. 
<smiles>CN(CCCCCCN(C)C(=O)Oc1ccc[n+](C)c1)C(=O)Oc1ccc[n+](C)c1</smiles><smiles>CN(C)C(=O)Oc1ccc[n+](C)c1</smiles>

Pyridostigmine<smiles>CN(C)C(=O)Oc1cccc([N+](C)(C)C)c1</smiles>

Neostigmine<smiles>CC[N+](CC)(CCNC(=O)C(=O)NCC[N+](CC)(CC)Cc1ccccc1Cl)Cc1ccccc1Cl</smiles>

Ambenonium

Fig. 1. Structures of Reversible Carbamate Inhibitors (Distigmine, Pyridostigmine, Neostigmine, and Ambenonium) of Cholinesterase (ChE)

rhAChE in the amount of $3.6 \mu \mathrm{g}$ used in this series of experiments was found to decompose acetylthiocholine (ATCh; $6.82 \mathrm{~mm}$ ) to produce thiocholine (TCh; $5.10 \pm 0.43 \mathrm{~mm}$ ). Furthermore, the absorbance changes attributed to the reaction of 5,5'-dithiobis(2-nitrobenzoic acid) (DTNB) with ATCh (negative control) were almost negligible; the absorbance change, which was expressed as the TCh concentration according to the obtained calibration curve $(y=0.3199 \cdot x)$, was $0.0170 \pm 0.0037 \mathrm{~mm}$.

The basic principle for measuring the AChE activity using a Nanosep ${ }^{\circledR} 10 \mathrm{~K}$ (hereafter, Nanosep ${ }^{\circledR}$ ) centrifugal device (Pall Corporation, Port Washington, NY, U.S.A.) is shown in Fig. 2A. This device is a centrifugal filtration unit with an attached ultrafiltration membrane $[10-\mathrm{kDa}$ molecular weight cutoff (MWCO)] and a microcentrifuge tube as a filtrate reservoir.

First, an rhAChE solution $(200 \mu \mathrm{L})$ was added to a Nanosep ${ }^{\circledR}$ column (the upper part above the ultrafiltration membrane) and then incubated for $30 \mathrm{~min}$ at $30^{\circ} \mathrm{C}$. Subsequently, ATCh $(75 \mathrm{~mm}, 20 \mu \mathrm{L})$ was added to the rhAChE solution and incubated for $3 \mathrm{~min}$ at $30^{\circ} \mathrm{C}$, resulting in ATCh decomposition into TCh and acetic acid, as shown in the chemical reaction formula (1):

$$
\mathrm{ATCh} \stackrel{\mathrm{AChE}}{\longrightarrow} \mathrm{TCh}+\text { Acetic acid }
$$

One minute after the completion of the 3-min incubation period, the Nanosep ${ }^{\circledR}$ device was centrifuged $\left(25-30^{\circ} \mathrm{C}\right.$, $5000 \times g, 5 \mathrm{~min}$ ) in a desktop micro-cooling centrifuge (Model 3520; Kubota Corporation, Tokyo, Japan). The large rhAChE $(65 \mathrm{kDa})$ could not traverse through the ultrafiltration membrane and became trapped on its upper side. The reaction product, TCh, and unreacted ATCh are sufficiently small to pass through the membrane and were collected in the bottom reservoir.

The reaction medium collected in the bottom reservoir was used for the measurement of AChE activity by the DTNB method, which is described in more detail in "Measurement of rhAChE activity using the DTNB method." rhAChE trapped above the ultrafiltration membrane was rinsed 2-3 times with
HBSS (200 $\mu$ L per rinse) using centrifugation and reused for the measurement of rhAChE activity.

Assessment of Inhibitory Effects of AChE Inhibitors on AChE Activity For one cycle of this series of experiments, two Nanosep ${ }^{\mathbb{B}}$ devices were used: one was a blank device $\left(\right.$ Device $_{\text {blank }}$ ), and the other was an enzyme-only control (Device $\left._{\text {control }}\right)$. Two to three additional Nanosep ${ }^{\circledR}$ devices were used for the assessment of the inhibitory effects of AChE inhibitors ( Device $_{x}$ ). HBSS $\left(200 \mu \mathrm{L}\right.$ ) was added to the Device ${ }_{\text {blank }}$ column, and the rhAChE solution $(200 \mu \mathrm{L})$ was added to the Device $_{\text {control }}$ and Device ${ }_{x}$ columns. Subsequently, according to the protocol shown in Fig. 2A, activities of rhAChE were assessed by measuring the production of TCh from ATCh [chemical reaction (1)]. Then, the Nanosep ${ }^{\circledR}$ columns were rinsed two to three times with HBSS to remove ATCh and TCh remaining in the column.

The subsequent experimental protocols are shown in Fig. 2B. First, HBSS $(190 \mu \mathrm{L})$ was added to all Nanosep ${ }^{\circledR}$ columns as a blank and to dissolve rhAChE trapped on the ultrafiltration membrane. Thereafter, distilled water $(10 \mu \mathrm{L})$ was added

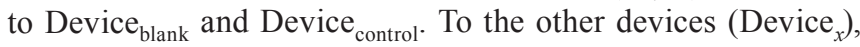
individual $\mathrm{ChE}$ inhibitors (distigmine, pyridostigmine, neostigmine, or ambenonium; $2 \times 10^{-5} \mathrm{M}, 10 \mu \mathrm{L}$ ) were added to a final concentration of $10^{-6} \mathrm{M}$. All Nanosep ${ }^{\circledR}$ devices were preincubated for $30 \mathrm{~min}$ at $30^{\circ} \mathrm{C}$ and then incubated for $3 \mathrm{~min}$ at $30^{\circ} \mathrm{C}$ after the addition of ATCh $(75 \mathrm{~mm}, 20 \mu \mathrm{L})$. After $1 \mathrm{~min}$, all Nanosep ${ }^{\circledR}$ devices were centrifuged (as described in "Measurement of rhAChE activity") to separate rhAChE from the free ChE inhibitors, ATCh, and TCh, which were collected in the lower-reservoir filtrate. The molecular weights of the $\mathrm{ChE}$ inhibitors (576 for distigmine, 261 for pyridostigmine, 303 for neostigmine, and 608 for ambenonium) are less than MWCO of Nanosep ${ }^{\circledR}$; therefore, all free $\mathrm{ChE}$ inhibitors were expected to pass through the ultrafiltration membrane. The filtrate was used for the measurement of AChE activity by the DTNB method (as described in "Measurement of rhAChE activity using the DTNB method"), and rhAChE trapped above the membrane was washed and reused as described in "Measure- 

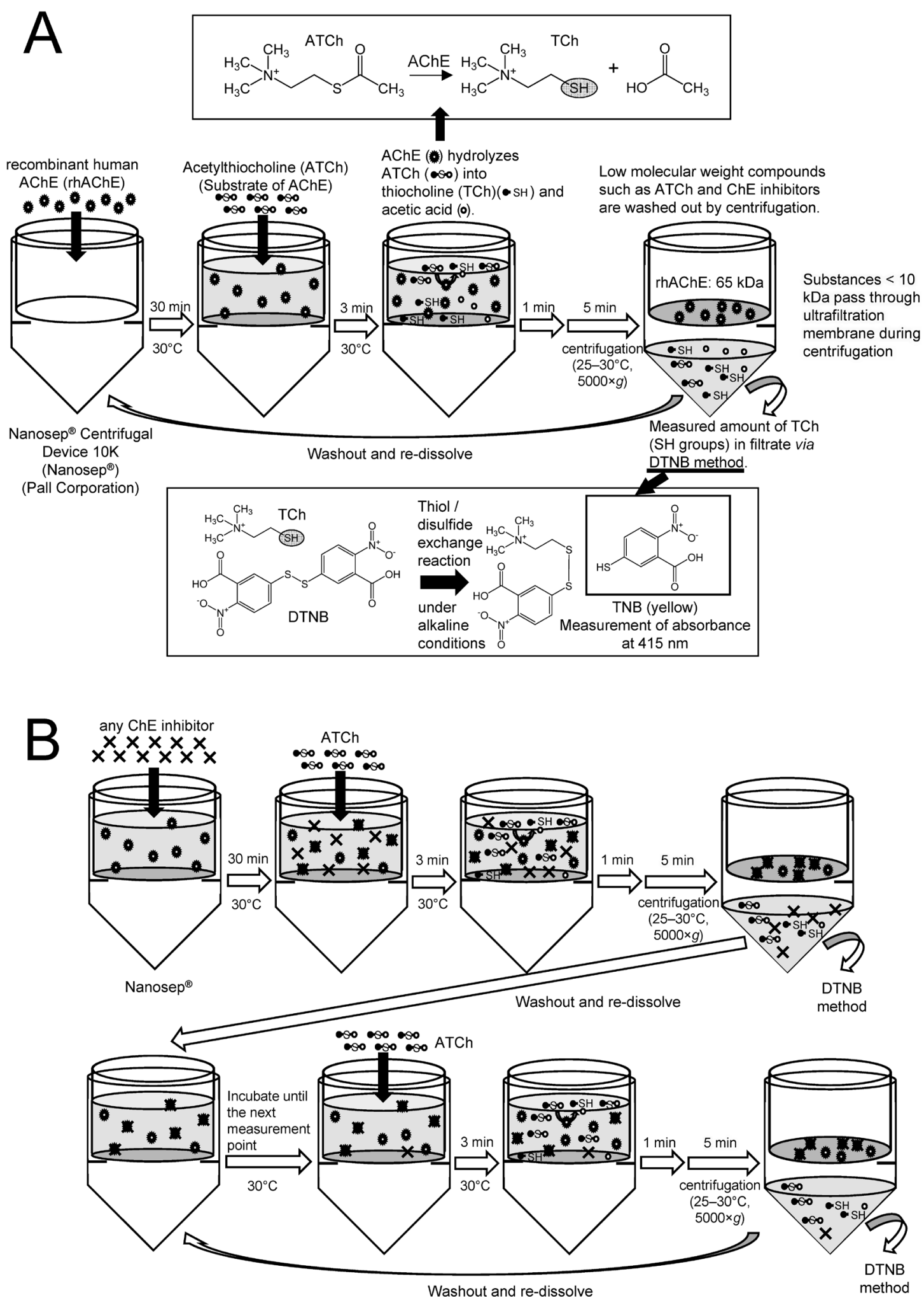

Fig. 2. The Basic Principle of Measuring the Acetylcholinesterase (AChE) Activity Using a Nanosep ${ }^{\circledR}$ 10K Centrifugal Device (Nanosep ${ }^{\circledR}$ )

A: Outline of the measurement of AChE activity. A recombinant human AChE (rhAChE) solution was added to the upper column of Nanosep ${ }^{\circledR}$ and incubated for 30 min. Thereafter, acetylthiocholine (ATCh) was added to the rhAChE solution to generate thiocholine (TCh) by decomposition of ATCh for $3 \mathrm{~min}$. After $1 \mathrm{~min}$, rhAChE and the reaction solution were separated by centrifugation $\left(25-30^{\circ} \mathrm{C}, 5000 \times \mathrm{g}, 5 \mathrm{~min}\right)$. The separated reaction solution (filtrate in the microtube reservoir) was mixed with 5,5'-dithiobis(2-nitrobenzoic acid) (DTNB). DTNB reacts with TCh to produce 2-nitro-5-thiobenzoate (TNB, yellow). By measuring the absorbance of this solution at $415 \mathrm{~nm}$, the amount of TCh was determined in the reaction solution, and this value was used for the calculation of AChE activity. rhAChE remaining on the ultrafiltration membrane was washed with Hanks' balanced salt solution (HBSS) and redissolved in HBSS. B: Outline of the washout protocol for cholinesterase (ChE) inhibitors. First, a ChE inhibitor was added to the rhAChE solution and incubated for $30 \mathrm{~min}$ to inhibit the AChE activity. After that, ATCh was added, and the mixture was incubated, similar to the protocol shown in Fig. 2A. Thereafter, rhAChE and the reaction solution were separated by ultrafiltration, which resulted in the transfer of unbound ChE inhibitors to the filtrate reservoir. rhAChE remaining on the ultrafiltration membrane was washed with and dissolved in HBSS. After that, the protocol shown in Fig. 2B was repeated for $6 \mathrm{~h}$ or $48 \mathrm{~h}$ after the washout of $\mathrm{ChE}$ inhibitors, and changes in the AChE activity were measured. 
ment of rhAChE activity."

Thereafter, HBSS $(200 \mu \mathrm{L})$ was added to all columns, and this was denoted as time zero of ChE inhibitor washout. Subsequently, by repeating these procedures, changes in $\mathrm{AChE}$ activity were measured every $30 \mathrm{~min}$ until $6 \mathrm{~h}$ after the washout of the ChE inhibitors or until $48 \mathrm{~h}$ (at 1, 3, 6, 12, 18, 24, $30,36,42$, and $48 \mathrm{~h}$ ).

Measurement of $\operatorname{rhAChE}$ Activity Using the DTNB Method The rhAChE activity was measured by the DTNB method (Fig. 2A). Briefly, to assay the amount of TCh produced in the reaction, the filtrate in the lower reservoir was mixed with DTNB $(5 \mathrm{~mm})$. The absorbance at $415 \mathrm{~nm}$ was then measured using a plate reader (Infinite ${ }^{\circledR}$ F200 PRO; Tecan, Männedorf, Switzerland).

Generally, the activity of AChE and, thus, the absorbance intensity decrease over time because of sequential processing of the enzyme. This leads to reduced measurement sensitivity and data reliability. To avoid this potential problem, the volume $(\mu \mathrm{L})$ ratio of the filtrate to DTNB was increased from $10: 190$ to $80: 120$, according to the time-dependent decrease in the absorbance of the Device control $_{\text {filtrate. The absorbance }}$ measurements were performed in duplicate.

Calculation of AChE Activity The activity of rhAChE was calculated based on the absorbance data, as described below.

First, to correct for device variations, the AChE activity in each device $\left(\mathrm{DA}_{x}\right)$ was obtained before the treatment with $\mathrm{ChE}$ inhibitors as a relative value against the AChE activity in the control device, according to Eq. 2:

$$
\mathrm{DA}_{x}=\frac{\left(A_{x, \text { before treatment }}-A_{\text {blank }}\right)}{\left(A_{\text {control }}-A_{\text {blank }}\right)}
$$

where $A_{x, \text { before treatment }}$ is the DTNB assay absorbance of the ultrafiltration liquid in Device $_{x}$ before treatment with $\mathrm{ChE}$ inhibitors; $A_{\text {control }}$ is the DTNB assay absorbance of the ultrafiltration liquid in Device control $_{\text {; }}$ and $A_{\text {blank }}$ is the DTNB assay absorbance of the ultrafiltration liquid in Device blank $_{\text {. }}$.

Next, the AChE activity of Device ${ }_{x} t$ h after the washout of ChE inhibitor $x$ (AChE activity ${ }_{x, t}$ ) was calculated according to Eq. 3. The AChE activity ${ }_{x, t}$ was corrected with the $\mathrm{DA}_{x}$ value from Eq. 2 and also with the AChE activity of Device control . The latter correction was required because of reduced AChE activities owing to the extended sequential processing mentioned in "Measurement of rhAChE activity using the DTNB method."

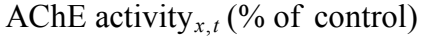

$$
\begin{aligned}
& =\frac{\left(A_{x, t}-A_{\mathrm{blank}, t}\right)}{\left(A_{\mathrm{control}, t}-A_{\mathrm{blank}, t}\right) \cdot \mathrm{DA}_{x}} \times 100
\end{aligned}
$$

where $A_{x, t}$ is the DTNB assay absorbance of the ultrafiltration liquid of Device $_{x} t \mathrm{~h}$ after the washout of ChE inhibitor $x ; A_{\text {control, } t}$ is the DTNB assay absorbance of the ultrafiltration liquid of Device control $t \mathrm{~h}$ after the washout of $\mathrm{ChE}$ inhibitor $x$; $A_{\text {blank }, t}$ is the DTNB assay absorbance of the ultrafiltration liquid of Device blank $t \mathrm{~h}$ after the washout of ChE inhibitor $x$.

The inhibitory ratio of the AChE activity $\left(\mathrm{AChE} \mathrm{IR}_{x, t}\right) t \mathrm{~h}$ after the washout of ChE inhibitor $x$ was calculated according to Eq. 4:

$$
\operatorname{AChE~IR~}_{x, t}(\%)=100-\mathrm{AChE}_{\text {activity }_{x, t}}
$$

The dissociation rate constant $\left(k_{\text {diss }}\right)$ was obtained using the modified methods reported by Perola et al. ${ }^{19)}$ and Bartolini et $a l .{ }^{20)}$ whose principles are described below.

The reaction of $\mathrm{AChE}(\mathrm{EH})$ with a $\mathrm{ChE}$ inhibitor (AB) will produce a complex of AChE-ChE (EA) through an intermediate product $(\mathrm{EH} \cdots \mathrm{AB})$ [reaction $(5)]$ :

$$
\mathrm{EH}+\mathrm{AB} \rightleftarrows \mathrm{EH} \cdots \mathrm{AB} \rightarrow \mathrm{EA}+\mathrm{HB}
$$

Thereafter, EA undergoes decarbamoylation with water to produce recovered $\mathrm{EH}$ and $\mathrm{AOH}$ (product of decomposition of the ChE inhibitor) [reaction (6)]:

$$
\mathrm{EA}+\mathrm{H}_{2} \mathrm{O} \stackrel{k_{\text {diss }}}{\longrightarrow} \mathrm{EH}+\mathrm{AOH}
$$

In our experimental protocol, only the dissociation reaction proceeded according to reaction (6) after ultrafiltration because the unreacted $\mathrm{ChE}$ inhibitor molecules were removed.

In reaction (6), the effects of water are negligible, and thus, this reaction will proceed according to pseudo-first-order kinetics. Therefore, the elimination rate of EA is obtained according to Eq. 7:

$$
-\frac{\mathrm{d}[\mathrm{EA}]}{\mathrm{d} t}=k_{\mathrm{diss}, x} \cdot[\mathrm{EA}]
$$

where [EA] is the concentration of EA, and $k_{\text {diss } x}$ is the dissociation rate constant of the $\mathrm{ChE}$ inhibitor. If Eq. 7 is integrated from 0 to $t \mathrm{~h}$, Eq. 8 is obtained:

$$
\ln \frac{[\mathrm{EA}]_{t}}{[\mathrm{EA}]_{0}}=-k_{\mathrm{diss}, x} \cdot t
$$

where $[\mathrm{EA}]_{t}$ and $[\mathrm{EA}]_{0}$ are the concentrations of EA at $t$ and $0 \mathrm{~h}$, respectively, in the presence of the $\mathrm{ChE}$ inhibitor.

The inhibitory ratio AChE IR, which is shown in Eq. 4, can also be calculated using Eq. 9:

$$
\mathrm{AChE} \mathrm{IR}_{x, t}(\%)=\frac{[\mathrm{EA}]_{t}}{([\mathrm{EA}]+[\mathrm{EH}])_{\text {total }}} \times 100
$$

where $([\mathrm{EA}]+[\mathrm{EH}])_{\text {total }}$ is the total concentration of $\mathrm{AChE}$ $(\mathrm{EA}+\mathrm{EH})$. In the presence of the $\mathrm{ChE}$ inhibitor and at $t=0 \mathrm{~h}$, Eq. 9 becomes Eq. 10:

$$
\operatorname{AChE~IR~}_{x, 0}(\%)=\frac{[\mathrm{EA}]_{0}}{([\mathrm{EA}]+[\mathrm{EH}])_{\text {total }}} \times 100
$$

If Eq. 9 is divided by Eqs. 10, 11 are obtained:

$$
\frac{\mathrm{AChE} \mathrm{IR}_{x, t}}{\mathrm{AChE} \mathrm{IR}_{x, 0}}=\frac{[\mathrm{EA}]_{t}}{[\mathrm{EA}]_{0}}
$$

If the value of $[\mathrm{EA}]_{t} /[\mathrm{EA}]_{0}$ from Eq. 11 is substituted into Eq. 8, 12 are obtained:

$$
\ln \frac{\mathrm{AChE} \mathrm{IR}_{x, t}}{\operatorname{AChE~IR~}_{x, 0}}=-k_{\text {diss }, x} \cdot t
$$

where $\mathrm{AChE} \mathrm{IR}_{x, t}$ is the inhibitory ratio of the $\mathrm{AChE}$ activity $t$ hours after the washout, and $\mathrm{AChE} \mathrm{IR}_{x, 0}$ is the inhibitory ratio of the $\mathrm{AChE}$ activity at $0 \mathrm{~h}$ in the presence of the $\mathrm{ChE}$ inhibitor.

AChE IR IR, $_{\text {can }}$ be obtained from the absorbance measurement as shown in Eq. 4. Therefore, using the absorbance data, $\left(\mathrm{AChE} \mathrm{IR}_{x, t} / \mathrm{AChE} \mathrm{IR}_{x, 0}\right.$ ) was calculated and plotted against $t$ hours. The plot was then fitted with a straight line, and 


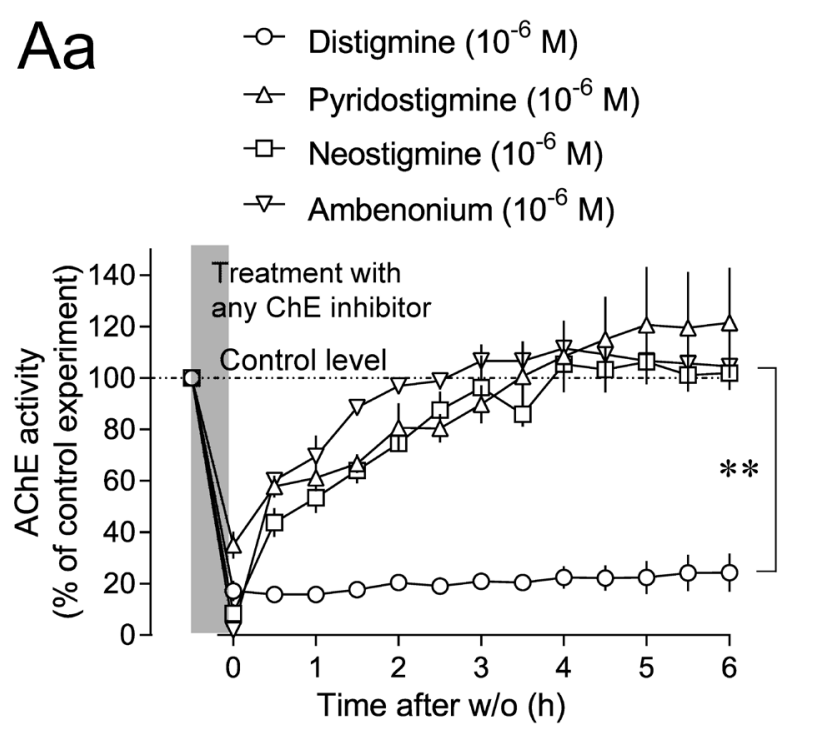

\section{$\mathrm{Ab}$}

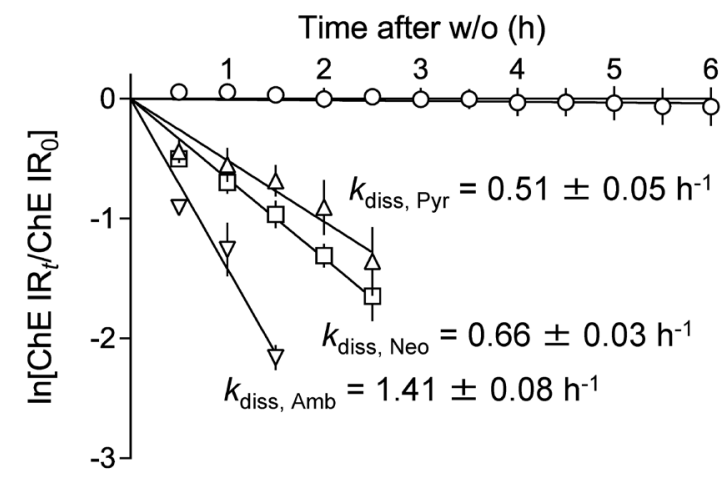

$\mathrm{Ba}$
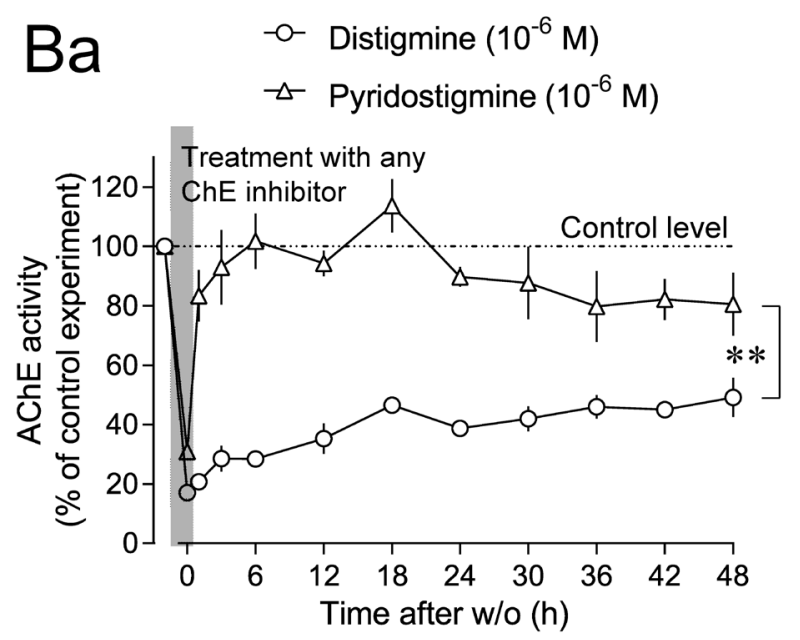

$\mathrm{Bb}$

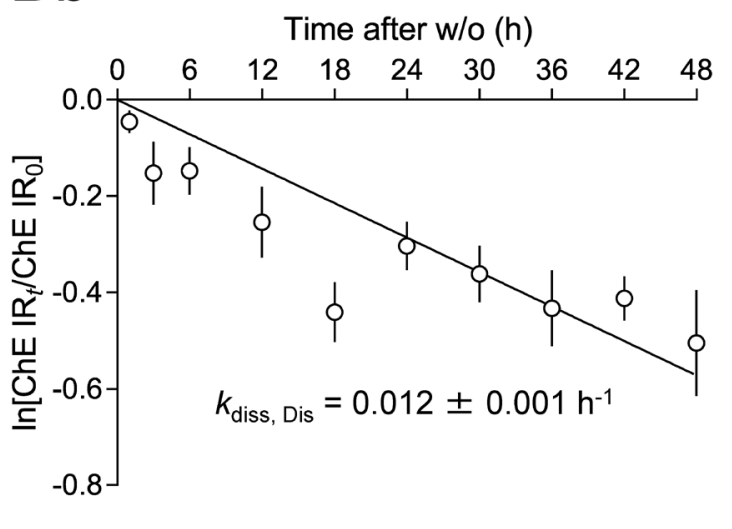

Fig. 3. Time Courses of Changes in Recombinant Human Acetylcholinesterase (rhAChE) Activity after Treatment with Distigmine, Pyridostigmine, Neostigmine, and Ambenonium and Subsequent Washout of the Drugs

Aa: Time courses of changes in the rhAChE activity after treatment with each cholinesterase (ChE) inhibitor (each $\left.10^{-6} \mathrm{M}\right)$ for $6 \mathrm{~h}$ after the inhibitor was washed out. The activity of rhAChE was expressed as a percentage relative to that in the control in the absence of ChE inhibitors $(100 \%)$. Data are shown as the means \pm S.E.M. $(n=4$, except pyridostigmine, where $n=5$ ). $* * p<0.01$, distigmine $v s$. other ChE inhibitors $6 \mathrm{~h}$ after the washout. Ab: The plot used to obtain the dissociation rate constant of each $\mathrm{ChE}$ inhibitor shown in Fig. 3Aa. Ba: Time courses of changes in the rhAChE activity after treatment with distigmine and pyridostigmine (each $\left.10^{-6} \mathrm{M}\right)$ until $48 \mathrm{~h}$ after the washout. The activity of rhAChE was expressed relative to that in the control in the absence of ChE inhibitors $(100 \%)$. Data are shown as the means \pm S.E.M. $(n=3)$. $*_{*}^{*} p<0.01$ at $48 \mathrm{~h}$ after the washout. Bb: The plot used to obtain the dissociation rate constant of distigmine shown in Fig. $3 \mathrm{Ba}$.

$k_{\text {diss }}$ was obtained using its slope (Figs. 3Ab, Bb). GraphPad Prism $^{\mathrm{TM}}$ (version 6.07; GraphPad Software, San Diego, CA, U.S.A.) was used for the line fitting.

Since reaction (6) proceeds according to pseudo-first-order kinetics, the dissociation half-life $\left(t_{1 / 2}\right)$ for each $\mathrm{ChE}$ inhibitor was calculated according to Eq. 13:

$$
t_{1 / 2}(\mathrm{~h})=\frac{\ln 2}{k_{\mathrm{diss}, x}}
$$

Measurement of Inhibitory Effects of ChE Inhibitors The thawed rhAChE stock solution was diluted in HBSS to a concentration of $0.5 \mu \mathrm{g} / \mathrm{mL}$ ( $c a$. 200-fold) to be used in the following experiments. rhAChE used in this series of experiments decomposed ATCh $(0.952 \mathrm{~mm})$ in a well of a 96 -well plate to produce TCh at a rate of $0.0134 \pm 0.0012 \mathrm{~mm} / \mathrm{min}$.

First, the diluted rhAChE solution $(50 \mu \mathrm{L})$ and DTNB $(5 \mathrm{~mm}$, $140 \mu \mathrm{L}$ ) were added to each well of a 96-well plate and incubated for $10 \mathrm{~min}$ at $30^{\circ} \mathrm{C}$. Subsequently, the test $\mathrm{ChE}$ inhibitors $\left(2 \times 10^{-9}-2 \times 10^{-3} \mathrm{M}, 10 \mu \mathrm{L}\right)$ were added to their corresponding wells so that their final concentrations were $10^{-10}-10^{-4} \mathrm{M}$ and incubated for $30 \mathrm{~min}$ at $30^{\circ} \mathrm{C}$.

After the incubation, ATCh $(75 \mathrm{~mm}, 10 \mu \mathrm{L})$ was added to each well, and the absorbance at $415 \mathrm{~nm}$ was then measured every $1 \mathrm{~min}$ for $10 \mathrm{~min}$. The obtained absorbance changes for the 10 -min measurement were then converted to absorbance changes per minute $\left(\Delta A_{x} / \mathrm{min}\right)$, and the activity of $\mathrm{AChE}$, which was unaffected by the test $\mathrm{ChE}$ inhibitors, was calculated according to Eq. 14:

$$
\operatorname{AChE} \text { activity }(\%)=\frac{\Delta A_{x}-\Delta A_{\text {blank }}}{\Delta A_{\text {control }}-\Delta A_{\text {blank }}} \times 100
$$

where $\Delta A_{\text {control }}$ is the absorbance change per min in the well to which distilled water $(10 \mu \mathrm{L})$ was added instead of a $\mathrm{ChE}$ inhibitor; $\Delta A_{\text {blank }}$ is the absorbance change per minute in the well to which HBSS $(50 \mu \mathrm{L})$ was added instead of the rhAChE solution and distilled water $(10 \mu \mathrm{L})$ was added instead of a 
ChE inhibitor.

The calculated AChE activity was plotted as a function of the ChE inhibitor concentration and fitted to Eq. 15:

$$
Y=\frac{100}{1+10^{\left(\log \mathrm{IC}_{50}-\log X\right) \times n_{\mathrm{H}}}}
$$

where $Y$ is the AChE activity (\%); $X$ is the ChE inhibitor concentration $(\mathrm{M}) ; n_{\mathrm{H}}$ is the Hill coefficient; and $\mathrm{IC}_{50}$ is the $\mathrm{ChE}$ inhibitor concentration inhibiting the AChE activity by $50 \%$.

Curve fitting was performed using GraphPad Prism ${ }^{\mathrm{TM}}$. The $\mathrm{IC}_{50}$ values were converted to their negative logarithms $\left(\mathrm{pIC}_{50}\right)$ to perform statistical analysis.

Drugs and Reagents The following drugs were used: distigmine bromide (Torii Pharmaceutical Co., Ltd., Tokyo, Japan), neostigmine bromide (Sigma-Aldrich), pyridostigmine bromide (MP Biomedicals, Santa Ana, CA, U.S.A.), and ambenonium dichloride (Tocris Bioscience, Bristol, U.K.). ATCh iodide and DTNB were purchased from Tokyo Chemical Industry Co., Ltd. (Tokyo, Japan), and TCh iodide was purchased from BOC Sciences (Shirley, NY, U.S.A.).

ATCh was dissolved in $0.1 \mathrm{M}$ phosphate buffer, $\mathrm{pH} 7.4$ to obtain a 20 or $75 \mathrm{~mm}$ stock solution. DTNB was dissolved in $0.1 \mathrm{M}$ phosphate buffer, $\mathrm{pH} 7.4$ to obtain a $5 \mathrm{~mm}$ stock solution. TCh was dissolved in $0.1 \mathrm{M}$ phosphate buffer, $\mathrm{pH} 7.4$ or HBSS to obtain a $10 \mathrm{~mm}$ stock solution and diluted with the dissolution buffer. All drugs were prepared as aqueous solutions and diluted with distilled water.

Statistical Analysis Data are expressed as the means \pm standard error of the mean (S.E.M.), and $n$ refers to the number of replicates. Significant differences between the means were evaluated using Tukey's multiple comparison tests after two-way factorial ANOVA using GraphPad Prism ${ }^{\mathrm{TM}}$. A $p$-value of less than 0.05 was considered statistically significant.

\section{RESULTS}

Inhibitory Effects of Distigmine, Pyridostigmine, Neostigmine, and Ambenonium on rhAChE Activity Measured for $6 \mathrm{~h}$ after Drug Washout Figure 3Aa shows the time-dependent changes in enzyme activity of rhAChE after treatment with distigmine, pyridostigmine, neostigmine, or ambenonium (each $10^{-6} \mathrm{M}$ ), measured for $6 \mathrm{~h}$ after washout of the drugs. Distigmine, pyridostigmine, neostigmine, and ambenonium initially reduced the rhAChE activity to $17.2 \pm 3.4$, $35.1 \pm 5.3,8.4 \pm 3.6$, and $2.0 \pm 0.5 \%$, respectively, compared to the activity $(100 \%)$ observed in the absence of a ChE inhibitor. After pyridostigmine, neostigmine, and ambenonium were washed out, the AChE activity was gradually restored, reaching the control levels after $2-4 \mathrm{~h}$. The $k_{\text {diss }}$ values were calculated to be $0.51 \pm 0.05,0.66 \pm 0.03$, and $1.41 \pm 0.08 \mathrm{~h}^{-1}$ for pyridostigmine, neostigmine, and ambenonium, respectively. The dissociation $t_{1 / 2}$ values for these inhibitors were calculated to be $1.36,1.05$, and $0.49 \mathrm{~h}$, respectively (Fig. $3 \mathrm{Ab}$ ).

On the other hand, the AChE activity barely recovered after inhibition with distigmine. The AChE activity $6 \mathrm{~h}$ after distigmine was washed out was $24.4 \pm 7.4$ vs. $17.2 \pm 3.4 \%$ at $0 \mathrm{~h}$ (Fig. 3Aa). Therefore, the activity of AChE treated with distigmine remained significantly reduced $(p<0.01)$ over $6 \mathrm{~h}$, despite the removal of the drug, as compared to the AChE activities observed after removal of the other ChE inhibitors.

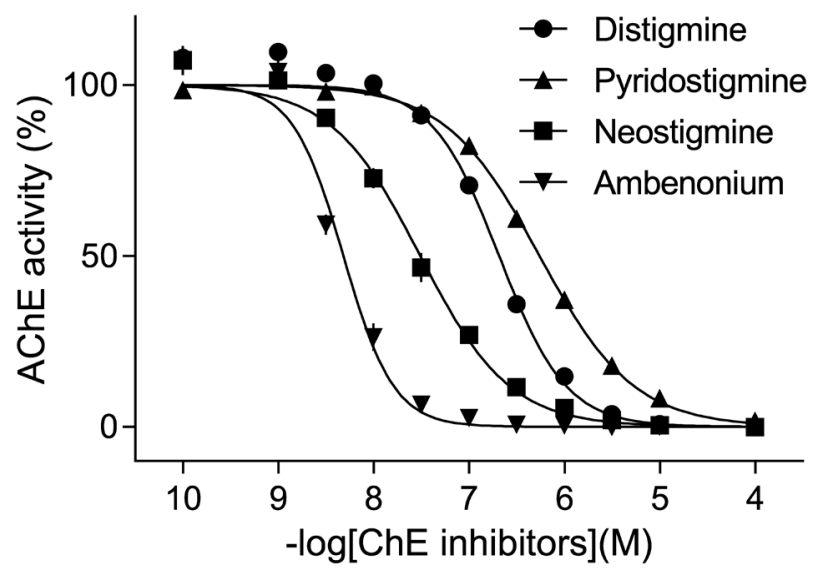

Fig. 4. Concentration-Response Curves for Inhibitory Effects of Distigmine, Pyridostigmine, Neostigmine, and Ambenonium on the Activity of Recombinant Human Acetylcholinesterase (rhAChE)

The rhAChE activity was expressed as a percentage of that in the control in the absence of cholinesterase (ChE) inhibitors (100\%). Data are shown as the means \pm S.E.M. $(n=4-5)$.

Inhibitory Effects of Distigmine and Pyridostigmine on rhAChE Activity Measured for $48 \mathrm{~h}$ after Drug Washout Figure $3 \mathrm{Ba}$ shows the enzyme activities of rhAChE after treatment with distigmine and pyridostigmine (each $10^{-6} \mathrm{M}$ ) and the time-dependent changes in the activity over a 48-h period after the inhibitors were washed out. Distigmine and pyridostigmine initially reduced the rhAChE activity to $17.1 \pm 1.4$ and $30.9 \pm 1.8 \%$, respectively, compared to the corresponding activity $(100 \%)$ measured in the absence of the ChE inhibitors. The AChE activity inhibited by pyridostigmine was gradually restored after the drug was washed out, similar to that shown in Fig. 3Aa, and was completely restored to the control level after $6 \mathrm{~h}$. The AChE activity inhibited by distigmine was restored to $49.2 \pm 6.6 \% 48 \mathrm{~h}$ after drug washout. However, the activity was still significantly lower than that of AChE treated with pyridostigmine $(p<0.01)$. The $k_{\text {diss }}$ and dissociation $t_{1 / 2}$ values for distigmine were calculated to be $0.012 \pm 0.001 \mathrm{~h}^{-1}$ and $57.8 \mathrm{~h}$, respectively (Fig. 3Bb).

Comparison of Inhibitory Effects of Distigmine, Pyridostigmine, Neostigmine, and Ambenonium on $\operatorname{rhAChE}$ Activity Figure 4 shows the concentration-response relationships for the inhibitory effects of distigmine, pyridostigmine, neostigmine, and ambenonium on the activity of rhAChE. All ChE inhibitors tested in the present study inhibited the rhAChE activity in a concentration-dependent fashion $\left(10^{-10}-10^{-4} \mathrm{M}\right)$. The $\mathrm{pIC}_{50}$ values of these inhibitors were determined as follows: $8.32 \pm 0.03$ (ambenonium) $>7.51 \pm 0.03$ (neostigmine) $>6.68 \pm 0.03$ (distigmine) $>6.26 \pm 0.04$ (pyridostigmine).

\section{DISCUSSION}

This study was carried out to determine the duration of distigmine inhibition of the rhAChE activity compared to that of other ChE inhibitors and to elucidate the mechanisms of persistent inhibition of the UB contraction or motility by distigmine. The results showed that unlike other ChE inhibitors, distigmine had a pharmacological feature making it difficult for the drug to dissociate from AChE. This feature may partly explain why distigmine exhibits a long-lasting effect on the 
UB contraction and motility as a treatment for an underactive bladder.

The method measuring $k_{\text {diss }}$ of ChE inhibitors for rhAChE, shown in Fig. 2B, was designed to remove unbound $\mathrm{ChE}$ inhibitor molecules by ultrafiltration, thus stopping the inhibition of rhAChE, while leaving the enzyme on the membrane filter. This process allowed the dissociation reaction [reaction (6)] to proceed selectively. Other experimental methods used to calculate $k_{\text {diss }}$ values of ChE inhibitors included HPLC ${ }^{20)}$ and dialysis membranes. ${ }^{19)}$ The greatest advantage of the method used in the present study is that no special equipment such as an HPLC instrument is required. When compared to the method using dialysis membranes, the separation of unreacted $\mathrm{ChE}$ inhibitors from $\mathrm{AChE}$ in our study could be completed within a relatively short time $(5 \mathrm{~min})$ versus $24 \mathrm{~h}$ required for dialysis membrane methods.

The $k_{\text {diss }}$ value of pyridostigmine was calculated to be $0.51 \pm 0.05 \mathrm{~h}^{-1}$ at $30^{\circ} \mathrm{C}$ in our study, which corresponds well to the value $\left(0.74 \pm 0.02 \mathrm{~h}^{-1}\right.$ at $\left.25^{\circ} \mathrm{C}\right)$ obtained by HPLC using an rhAChE-fixed column bioreactor. ${ }^{20)}$ Therefore, the reliability of the results obtained by our method seems to be high. Furthermore, the $k_{\text {diss }}$ values of pyridostigmine and neostigmine determined in the present study $\left(0.51 \pm 0.05\right.$ and $0.66 \pm 0.03 \mathrm{~h}^{-1}$, respectively) were also consistent with the values obtained in guinea pig UB smooth muscle tissues at $37^{\circ} \mathrm{C}(0.50 \pm 0.04$ and $0.40 \pm 0.02 \mathrm{~h}^{-1}$, respectively). ${ }^{18)}$ However, the value obtained for ambenonium with rhAChE $\left(1.41 \pm 0.08 \mathrm{~h}^{-1}\right)$ was greater than that obtained with guinea pig UB smooth muscle tissue $\left(0.61 \pm 0.04 \mathrm{~h}^{-1}\right)$. Although we do not have a clear explanation for this difference at present, one plausible explanation could be the presence of $\mathrm{Cl}$ in the structure of ambenonium (Fig. 1). Ambenonium might be trapped in the lipid bilayers of UB smooth muscle tissue membranes because of the $\mathrm{Cl}$ groups and gradually released to bind to AChE, which would decrease the apparent $k_{\text {diss }}$ value when using smooth muscle tissue.

Our previous results ${ }^{17,18)}$ have suggested two possibilities to explain why distigmine inhibits the UB motility for so long. One is that distigmine resists the dissociation from $\mathrm{AChE}$ after binding, and the other is that distigmine, which is trapped in the UB smooth muscle plasma membrane, is gradually released to inhibit AChE.

The present study used purified rhAChE, which ruled out the latter possibility and also showed that distigmine strongly binds to rhAChE compared to binding of other ChE inhibitors. One plausible explanation for this property of the drug could be that distigmine contains a long-chain alkyl group in its structure (Fig. 1). Concerning this feature, Perola et al. ${ }^{19)}$ have reported that the introduction of a long-chain alkyl group into physostigmine greatly reduced its $k_{\text {diss }}$ compared to that of the parent physostigmine. Perola et al. ${ }^{19)}$ speculated that the introduction of a hydrophobic group prevents water molecules, which are needed for decarbamoylation, from accessing the AChE active site. Therefore, the presence of a long-chain alkyl group in the distigmine molecule prevents the water moleculeinduced dissociation from $\mathrm{AChE}$ and thus, makes the dissociation time of distigmine 40-120 times longer than that of other ChE inhibitors. The dissociation $t_{1 / 2}$ of distigmine $(57.8 \mathrm{~h})$ was much greater than the elimination half-life of distigmine from the blood ( $c a .0 .7 \mathrm{~h}) .{ }^{17)}$ Therefore, the persistent inhibition by intravenous distigmine is attributed not to its slow elimination from the blood but to a very slow dissociation from $\mathrm{AChE}$ in the UB smooth muscle. Furthermore, based on the $\mathrm{pIC}_{50}$ values, the affinities of the tested $\mathrm{ChE}$ inhibitors could be ranked as follows: ambenonium $>$ neostigmine $>$ distigmine $>$ pyridost gmine. Therefore, the possibility of a higher affinity of distigmine for AChE compared to those of the other ChE inhibitors can be ruled out as an explanation for the much smaller $k_{\text {diss }}$ value of distigmine against $\mathrm{AChE}$ compared to those of the other ChE inhibitors.

\section{CONCLUSION}

Distigmine does not easily dissociate from AChE. This pharmacological feature of distigmine accounts, at least partly, for its very long-lasing potentiating effects on the UB motility as a treatment for an underactive bladder.

Acknowledgment Distigmine bromide was a kind gift from Torii Pharmaceutical Co., Ltd. (Tokyo, Japan).

Conflict of Interest The authors declare no conflict of interest.

\section{REFERENCES}

1) Schmid O. Bis-carbamic acid ester compounds, and a process of making same. U.S. Patent 2789981 (1957).

2) Ishigaki K, Murakami T, Ito $Y$, Yanagisawa A, Kodaira K, Shishikura K, Suzuki H, Hirayama Y, Osawa M. Treatment approach to congenital myasthenic syndrome in a patient with acetylcholine receptor deficiency. No To Hattatsu, 41, 37-42 (2009).

3) Ishikawa $\mathrm{S}$, Tsukahara $\mathrm{S}$, Sato $\mathrm{Y}$. Local administration of $1 \%$ ubretid in the handling of glaucoma, myasthenia gravis and esotropia. Ophthalmologica, 159, 339-362 (1969).

4) Cameron MD. Distigmine bromide (ubretid) in the prevention of postoperative retention of urine. J. Obstet. Gynaecol. Br. Commonw., 73, 847-848 (1966).

5) Yeo J, Southwell P, Hindmarsh E. Preliminary report on the effect of distigmine bromide on the neurogenic bladder. Med. J. Aust., 1, 116-120 (1973).

6) Philp NH, Thomas DG. The effect of distigmine bromide on voiding in male paraplegic patients with reflex micturition. Br. J. Urol., 52, 492-496 (1980).

7) Tanaka Y, Masumori N, Itoh N, Furuya S, Nishizawa O, Tsukamoto T. Symptomatic and urodynamic improvement by oral distigmine bromide in poor voiders after transurethral resection of the prostate. Urology, 57, 270-274 (2001)

8) Bougas DA, Mitsogiannis IC, Mitropoulos DN, Kollaitis GC, Serafetinides EN, Giannopoulos AM. Clinical efficacy of distigmine bromide in the treatment of patients with underactive detrusor. Int. Urol. Nephrol., 36, 507-512 (2004).

9) Emeryk E, Wasowicz B. Evaluation of "ubretid" (BC 51) in the treatment of myasthenia gravis. Neurol. Neurochir. Psychiatr. Pol., 13, 611-617 (1963).

10) Horinouchi $T$, Aoki $T$, Akiyama R, Ono $T$, Shibano $M$, Tanaka $\mathrm{Y}$, Koike K. Effects of distigmine, a long-acting cholinesterase inhibitor, on urinary bladder detrusor and urethra smooth muscles of guinea-pig: pharmacological analysis in vitro and in vivo. $\bar{O} y \bar{o}$ Yakuri, 64, 45-52 (2003).

11) Sekiya S, Ookawa N, Horinouchi T, Tanaka Y, Koike K. Effects of distigmine, a long-acting cholinesterase inhibitor, on urinary bladder contractile functions assessed by using cystometry method in anesthetized guinea-pigs. Ōyō Yakuri, 70, 29-34 (2006).

12) Sekiya S, Michikawa H, Tanaka Y, Koike K. Effects of distigmine 
on the intraurethral pressure of anesthetized guinea-pigs. $\bar{O} y \bar{o}$ Yakuri, 71, 19-27 (2006).

13) Sekiya S, Takahashi H, Seki Y, Teraoka A, Aikawa N, Tanaka Y, Koike K. Comparison of the effects of distigmine and neostigmine on guinea-pig urinary bladder contractile functions assessed by in vivo and in vitro studies. $\bar{O} y \bar{o}$ Yakuri, 75, 85-96 (2008).

14) Obara K, Aikawa N, Sato K, Chino D, Tanaka Y. Comparison of the effects of distigmine and bethanechol on guinea-pig lower urinary tracts contractile functions assessed by in vivo and in vitro studies. $\bar{O} y \bar{o}$ Yakuri, 85, 101-114 (2013).

15) Obara K, Chino D, Tanaka Y. The recovery effects of distigmine on guinea pig detrusor underactivity induced by anticholinergic drugs. Ōyō Yakuri, 91, 25-39 (2016).

16) Obara K, Kobayashi Y, Chino D, Tanaka Y. Effects of distigmine on electrical field stimulation-induced contraction of mouse urinary bladder smooth muscles. Pharmacology, 99, 106-113 (2017).
17) Obara K, Chino D, Tanaka Y. Distigmine bromide produces sustained potentiation of guinea-pig urinary bladder motility by inhibiting cholinesterase activity. Biol. Pharm. Bull., 40, 807-814 (2017).

18) Obara K, Ogawa T, Chino D, Tanaka Y. The long-lasting enhancing effect of distigmine on acetylcholine-induced contraction of guinea pig detrusor smooth muscle correlates with its anticholinesterase activity. Biol. Pharm. Bull., 40, 1092-1100 (2017).

19) Perola E, Cellai L, Lamba D, Filocamo L, Brufani M. Long chain analogs of physostigmine as potential drugs for Alzheimer's disease: new insights into the mechanism of action in the inhibition of acetylcholinesterase. Biochim. Biophys. Acta, 1343, 41-50 (1997).

20) Bartolini M, Cavrini V, Andrisano V. Characterization of reversible and pseudo-irreversible acetylcholinesterase inhibitors by means of an immobilized enzyme reactor. J. Chromatogr. A, 1144, 102-110 (2007). 